
$\Omega$
(1)
Division of Pulmonary and Critical Care Medicine, Vanderbilt University Medical
Center, Nashville, TN, USA.

\title{
Pulmonary and critical care training in the USA
}

Pulmonary physician subspecialty training in the USA is typically offered in combination with critical care training. The Accreditation Council for Graduate Medical Education (ACGME) governs postgraduate medical training in the USA. Through the ACGME, there are 20 hospitals that offer pulmonary disease training alone and $>150$ programmes nationally that offer combined pulmonary and critical care medicine (PCCM) training [1]. Historically, sleep medicine training was also part of the formal training and programme graduates would be allowed to practice but sleep medicine now requires a separate year of fellowship training. Critical care training is accessible itself through a dedicated 2-year fellowship.

\section{Training path}

In the USA, medical training follows completion of one's undergraduate or university studies and begins with medical school. American medical schools are predominantly 4 years in length with a minority allowing a briefer stint of 3 years when combined with a specialised track in university. Following medical school, graduates choose their desired specialty and seek to obtain a training position through the formalised match process. Training positions are limited in every specialty, and are awarded to applicants based on a merit system of medical school grades, standardised test performance, letters of recommendation from consultants and individualised programme desires. Those desiring to enter pulmonary medicine must first complete a 3-year residency in internal medicine, with the first year known as internship. Following residency, one can apply for a subspecialty fellowship programme, which provides $2-3$ years of advanced clinical training.

\section{Programme structure}

Pulmonary disease programmes are 2 years in length and are comprised primarily of clinical training. Combined PCCM training programmes are 3 years in length and vary in the amount of clinical training based on hospital. The minimum amount of clinical training by ACGME standards is 18 months. At many programmes with academic interest, the remaining 18 months is spent engaging in research. The amount of research time can be variable though, with many programmes seeking to maximise clinical training. There is no minimum amount of time that must be strictly devoted to scholarly activity [2].

In terms of clinical training, $\geq 9$ months must be spent in devoted pulmonary training, which usually is comprised of time on the medical wards performing pulmonary consultations and managing an inpatient pulmonary service under the guidance of a teaching consultant. The remaining nine requisite months must be devoted to care of the critically ill patient in the intensive care setting. At least six of these months must be in the medical intensive care unit (ICU) setting while the remainder is spent in diverse ICU settings such as neurology, cardiovascular, trauma or burn ICUs (which are predominantly staffed by anaesthetists or surgeons).

PCCM fellowship offers many teaching opportunities as the medical ICU is a cornerstone of training in every internal medicine residency programme. Fellows frequently serve as the medical team leader under the supervision of a teaching consultant.

\section{Procedural competency}

Graduates of PCCM fellowships must demonstrate procedural competency in a broad array of both pulmonary and critical care procedures including endotracheal intubation, positive pressure ventilation management, fibreoptic bronchoscopy (including bronchoscopic procedures such as transbronchial biopsy, endobronchial biopsy and transbronchial needle aspiration), pulmonary function testing, lumbar puncture, paracentesis,
Cite as: Merrick C, Maldonado F. Pulmonary and critical care training in the USA. Breathe 2017; 13: e82-e83. 
thoracentesis, chest tube insertion and management, and arterial line and central venous catheter insertion, to name the major ones [2].

Formal endobronchial ultrasound, critical care ultrasound and echocardiography, and surgical chest tube insertion are not required but highly recommended in PCCM programmes due to their immense clinical utility.

\section{National trends}

PCCM, historically, has been less popular among American internal medicine residency graduates than other medical subspecialties such as cardiology and gastroenterology, but is becoming more competitive. Based on the match results of 2017 , $~ 55 \%$ of pulmonary or cardiology spots were filled by US graduates, with a similar number of applicants per spot in both groups [3]. Upon fellowship completion, a small percentage of graduates will stay on for additional research time on which to build their future careers in scholarly activity, many will pursue academic appointments either at their own or another institution, a small percentage will pursue advanced fellowship training (sleep medicine, interventional pulmonology or transplant), while a large number will go into community practice. A growing number of PCCM trained individuals are taking jobs as intensivists. The job market for these physicians is very favourable given a growing body of data and experience over the past 20 years that demonstrates improved ICU outcomes and decreased expense when staffed by dedicated intensivist physicians [4].

\section{Future direction}

PCCM is a burgeoning field and serves a core role in the US healthcare system given an ageing population and an ever-increasing burden of chronic disease. Technologies are advancing quickly and transforming our approach to PCCM, such as exciting advances in interventional pulmonology now allowing formerly surgical procedures (such as lung volume reduction) to be performed bronchoscopically, or the increasingly pervasive role of ultrasonography in the management of critically ill patients. Additionally, critical care, lung cancer, chronic obstructive pulmonary disease, pulmonary vascular disease and lung fibrosis (among others) are all areas rich with scholarly activity available to those in PCCM fellowships. As such, PCCM is likely to remain a top choice for internal medicine graduates in the USA for years to come.

\section{Conflict of interest}

None declared.

\section{References}

1. Accreditation Council for Graduate Medical Education. List of Programs by Specialty. https://apps.acgme.org/ads/public/ reports/report/1. Date last accessed: July 27, 2017.

2. Accreditation Council for Graduate Medical Education. Program Requirements for GME in Pulmonary Critical Care (Internal Medicine). https://www.acgme.org/Portals/0/PFAssets/ ProgramRequirements/156_pulmonary_critical_care_201707-01.pdf. Date last accessed: July 27, 2017.
3. National Resident Matching Program. Results and Data: 2017 Main Residency Match. Washington, National Resident Matching Program, 2017.

4. Burchardi $\mathrm{H}$, Moerer $\mathrm{O}$. Twenty-four hour presence of physicians in the ICU. Crit Care. 2001; 5: 131-137. 